\title{
Economy, Environment and Government: Study on the Path of Supply-Side Reform Forced by the Fog-Haze
}

\author{
Jiaorui Li, Ye Zhang, Shuang Zhang \\ Xi'an University of Finance and Economics, Xi'an, China \\ Email: jiaoruili@xaufe.edu.cn, 489422237@qq.com, 394133726@qq.com
}

How to cite this paper: Li, J.R., Zhang, Y. and Zhang, S. (2019) Economy, Environment and Government: Study on the Path of Supply-Side Reform Forced by the Fog-Haze. Journal of Applied Mathematics and Physics, 7, 281-297.

https://doi.org/10.4236/jamp.2019.72023

Received: January 2, 2019

Accepted: February 11, 2019

Published: February 14, 2019

Copyright $\odot 2019$ by author(s) and Scientific Research Publishing Inc. This work is licensed under the Creative Commons Attribution International License (CC BY 4.0).

http://creativecommons.org/licenses/by/4.0/

(c) (i) Open Access

\begin{abstract}
Unbalanced development in term as industrial structure and the efficiency use of energy have aggravated environmental pollution to different degrees resulting in the increase of range, time and degree of fog-haze. This, in turn, forced the government to carry out supply-side reforms, to improve energy efficiency and optimize the industrial structure to weaken the environmental pollution. To tackle these problems, this work provides an index system for the issues related to fog-haze, uses a non-linear ST-SVAR model to reflect the effects of industrial structure and energy use efficiency on fog-haze. Results indicated that: First, current industrial structure and energy use efficiency have greater impact on the comprehensive equation of fog-haze risk than itself. With the passage of time, this influence is still gradually expanding. Second, the equations of industrial structure and energy use efficiency are strongly influenced by themselves, and other variables as the current period have less impact on them. Finally, the non-linear or asymmetric relationship is shown among industrial structure, energy use efficiency, and the fog-haze comprehensive risk equation.
\end{abstract}

\section{Keywords}

Fog-Haze, Industrial Structure, Energy Use Efficiency, Non-Linear ST-SVAR Model, Supply-Side Reform

\section{Introduction}

Rapid economic growth has escorted economic development and has also caused serious environmental pollution. The most prominent performance is fog-haze pollution [1]. Fog-haze not only negatively affects human life, but also restricts 
the overall development of society [2]. The fog-haze pollution is mainly composed of inhalable particulate matters, sulfur dioxide, nitrogen oxides, etc., and its sources are diverse, such as industrial emissions, building dust, automobile exhaust, and even garbage incineration [3]. The fog-haze weather is usually formed by the mixing of various pollution sources [4].

The unique climatic conditions of Shaanxi Province and the industrial structure dominated by heavy industry have caused long-term fog-haze weather in winter. While heavy industry brings economic benefits to social development, it also brings environmental pollution, causing fog-haze, which in turn threatens the sustainable growth of the economy [5]. The abundant energy resources in northern Shaanxi have contributed a lot to the development of the economy, but the inefficient use of energy has also brought serious environmental pollution [6] [7]. The industrial structure dominated by heavy industry and the current status of energy use efficiency have caused pollution to the environment and also brought challenges to the balanced development of society.

What role does the government play in the face of environmental pollution and economic growth? The government must not only seek a way out for economic growth, reduce environmental pollution, but also balance the relationship between them. From the perspective of industrial structure and energy structure, the government will provide solutions for supply-side reform, optimize industrial structure, effectively solve overcapacity [8], improve energy use efficiency, reduce environmental pollution and provide long-term momentum for economic growth.

The current paper focuses on the linear relationship between industrial structure, energy use efficiency and fog-haze pollution, for example [9]-[18]. There are studies on supply-side structural reforms, for example [19] [20] [21] [22]. The impact of industrial structure and energy efficiency on the environment is complex and diverse, which has affected the life of the public, economic growth, and social stability to varying degrees. Therefore, it is very important to study the relationship between fog-haze pollution and industrial structure and energy use efficiency. It is helpful for analyzing industrial supply reform and energy supply reform, and provides a basis for supply-side structural reform.

The difference between this study and other studies is that the main body of this study includes fog-haze pollution, industrial structure and energy use efficiency. In addition, there is little research on the nonlinear relationship between smog pollution, industrial structure, and energy use efficiency. This paper uses the nonlinear ST-SVAR (Nonlinear Smooth Transition Structural Vector Autoregression) model, combining with the relevant data of Shaanxi Province in 2006-2017, and constructs a comprehensive index of haze risk, discussing the impact of current industrial structure and energy use efficiency on fog-haze pollution, thus providing data support for supply-side reforms.

The rest of the paper is organized as follows: Section 2 is Literature Review, Section 3 is Theoretical background, Section 4 is Method and Model, Section 5 is Empirical Results, and Section 6 is Conclusion and Policy Implications. 


\section{Literature Review}

Many scholars have studied the impact of industrial structure on fog-haze pollution. From the perspective of source control, through the expansion of a new energy-environment-economic model, integrating dynamic input-output models and multi-objective models, studying the impact of industrial structure adjustment on China's energy-saving and emission reduction targets, and screening three best solutions [23]. Liu analyzed the per capita industrial pollutant emissions of 285 prefecture level cities between the year 2003 and 2015, with the aim of revealing how industrial transfers affect the formation of convergence clubs [24]. The results shown that industrial restructuring and industrial transfer from eastern China to the west had led to significant differences in pollutant emissions in various cities. Ji conducted a quantitative analysis of the socioeconomic drivers of $\mathrm{PM}_{2.5}$ through evaluation [25]. The results show that income, urbanization and service industries have a significant impact on $\mathrm{PM}_{2.5}$ pollution. Income has always had a positive effect on $\mathrm{PM}_{2.5}$, but with the increase of urbanization level or income level, the effect will gradually decrease; there is an inverted $\mathrm{U}$-shaped relationship between urbanization and $\mathrm{PM}_{2.5}$.

Some scholars have also studied the effects of energy structure on fog-haze pollution. Guan discussed Beijing's regulation of energy structure adjustment measures from clean energy, coal pollution control for retailer, automobile exhaust and regional joint treatment, and then controls fog-haze [3]. Ma used the spatial Dubin model to analyze the relationship between energy structure, traffic patterns, and haze pollution. Measures to improve fog-haze pollution were proposed in the short-term and long-term, respectively [26]. Li employs the modified dynamic SBM model to analyze the energy efficiency and AQI efficiency of 31 cities in China from 2013 to 2016 [27]. The results show that for the performance of overall efficiency indicators, there are still 22 cities that need to significantly improve their overall efficiency. In order to better solve the problem of justice in the distribution of energy resources, Raphael proposed a new method, that is, these countries establish a sovereign wealth fund [28]. He proposed ensuring that justice is a key policy goal for energy taxation and aimed to contribute to the emerging literature of sovereign wealth funds.

Research on the supply-side structural reforms, Ram and Charles examined the impact of $\mathrm{CO}_{2}$ emission reductions in Indonesia during the period 2003-2017 from a perspective of long-term integrated resource planning [29]. The results of the study indicate that both supply and demand have an impact on reducing carbon dioxide, sulfur dioxide and nitrogen oxide emissions. However, the impact of supply plays a leading role. Lin and Su examined the main issues of high energy consumption, high energy structure pollution and serious overcapacity of the industrial system in China's supply system, and proposed the main content of supply-side reform [30]. In order to better deal with the relationship between steady growth, structural adjustment and risk prevention, Liu proposed that it is necessary to break through the dilemma of industrial struc- 
ture adjustment through supply-side structural reforms to improve economic efficiency and international competitiveness [31].

Although the previous literature covers many aspects, it is still not comprehensive enough: 1) From the perspective of research methods, most studies have discussed the linear relationship between smog pollution and industrial structure and energy structure, while ignoring the possibility of nonlinear relationships between them. 2) From the perspective of the research objective, environmental issues are not only related to economic development, industrial structure and energy structure, but also to government policy decisions.

Therefore, this article cites nonlinear thoughts to study the dynamic relationship between environment, economy, and government. According to the research results, the path selection of the government's supply-side reform was finally provided. This biggest difference between this article and the above article is that it takes into account the contemporaneous effects between endogenous variables.

Considering that the reacts about the risk of fog-haze quickly to changes in energy use efficiency and industrial structure, the current fog-haze risk comprehensive equation will include the current industrial structure and energy use efficiency, and measure the ventilator impact of both fog-haze risks.

\section{Theoretical Background}

Environmental pollution is not only related to economic development also has the role of government policies. The economy-environment-government is a subsystem that influences each other. Starting from the industrial structure and energy use efficiency, this section describes how the industrial structure and energy use efficiency, the environment, and the supply-side reform interact with each other.

First, the industrial structure, energy use efficiency and the environmental pollution present a game relationship. The industrial structure dominated by heavy industry has made great contributions to economic development, but, it has brought about fog-haze pollution that cannot be ignored [32] [33]. Environmental deterioration will in turn inhibit economic development. If things go on like this, this kind of game relationship will sink into dead circulation. This relationship between them has also prompted us to think about what kind of industrial structure can contribute to economic development and bring about the least fog-haze pollution.

Second, the fog-haze pollution and the supply-side reform have shown an overwhelming situation. Fog-haze pollution not only causes traffic congestion [34], also poses a serious threat to the health of the public. While inhibiting economic development, it also wastes natural resources. Reducing fog-haze pollution, supply-side reform has become an indispensable measure [35]. The government must take timely measures to start from the supply side, optimize supply, restrain the deterioration of fog-haze pollution, and minimize environmental damage [36]. If, the government remains indifferent, fog-haze pollution 
will become uncontrollable.

Third, there is a new relationship among industrial structure, energy use efficiency and supply-side reform. To solve the fog-haze pollution from the supply side, the government's work must focus on the main cause of fog-haze pollution [30]. The industrial structure needs to be reformed, in order to reduce heavy industry, develop the tertiary industry, and stimulate the continuous development of new industrial chains with high energy efficiency to promote balanced and comprehensive development of the industrial structure [37]. Starting from industrial supply and energy supply, search for the industrial model with healthy economic growth and less environmental pollution [32].

\section{Method and Model}

To answer the above questions, in this section, we will introduce the indicator system and model. The connection between theory and empirical study can clearly explain the relationship between the economic-environmental-government subsystems, thus providing support for the path selection of structural reforms on the supply side.

\subsection{The Comprehensive Index of Fog-Haze Risk}

In order to comprehensively measure the level of fog-haze pollution in life, we selected three indicators of air pollutants, industrial pollutant emissions [38], and transportation pressure.

The pollutants in the air can fully measure the concentration of inhalable particles and the emissions of $\mathrm{SO}_{2}$ and $\mathrm{NO}_{2}$. Industrial pollutants can fully measure the emissions of sulfur dioxide and nitrogen oxides in industrial activities. Transport pressure can measure the emissions of other sulfur dioxide and nitrogen oxides in life. Finally, we select the indicator system as shown in Table 1.

Take Shaanxi province as an example, getting the metrics in the above table, based on the air quality bulletin published and Shaanxi Statistical Yearbook from

Table 1. System of basic indicators of fog-haze risk.

\begin{tabular}{|c|c|c|c|}
\hline First grade indexes & $\begin{array}{l}\text { Second } \\
\text { grade indexes }\end{array}$ & Third grade indexes & Symbol \\
\hline \multirow{7}{*}{$\begin{array}{c}\text { The Comprehensive } \\
\text { Index of } \\
\text { Fog-Haze Risk }\end{array}$} & \multirow{3}{*}{$\begin{array}{c}\text { The pollutants } \\
\text { in the air }\end{array}$} & Particulate concentration & $f_{1}$ \\
\hline & & Average annual $\mathrm{SO}_{2}$ concentration & $f_{2}$ \\
\hline & & Average annual $\mathrm{NO}_{2}$ concentration & $f_{3}$ \\
\hline & \multirow{3}{*}{$\begin{array}{l}\text { Industrial } \\
\text { Pollutant } \\
\text { emissions }\end{array}$} & Total industrial emissions & $f_{4}$ \\
\hline & & Industrial sulfur dioxide emissions & $f_{5}$ \\
\hline & & Industrial smoke and dust emissions & $f_{6}$ \\
\hline & $\begin{array}{c}\text { Transportation } \\
\text { pressure }\end{array}$ & $\begin{array}{c}\text { Private vehicle } \\
\text { ownership/Road mileage }\end{array}$ & $f_{7}$ \\
\hline
\end{tabular}


2006 to 2017. Due to the limitation of obtaining $\mathrm{PM}_{2.5}$ which only appeared in recent years, this paper selects the average $\mathrm{PM}_{10}$ concentration to explain the effect of particulate concentration on the fog-haze index.

\subsection{The Industrial Structure and Energy Efficiency Index}

This study measures the impact of economic development on the environment from the perspective of industrial structure and energy use efficiency. It considers the heavy industry and energy industry with a large proportion of environmental pollution, and selects corresponding measurement indicators.

In order to study the imbalanced industrial structure and energy use efficiency in economic development, the work selected two indicators of the proportion of heavy industrial output in total industrial output value and conversion efficiency of energy processing as shown in Table 2.

\subsection{The Model}

Existing studies are based on linear assumptions to examine the economic-environment relationship. Is the relationship between them linear? To answer this question, it is necessary to measure the relationship between them with non-linear effects.

The traditional VAR model is usually used to describe the dynamic changes between sequences, without considering the contemporaneous relationship between variables as [39]. For illustrate the contemporaneous effects of the industrial structure and energy use efficiency on the comprehensive index of fog-haze risk, by resetting the VAR model as [40]:

$$
\mathrm{B} x_{t}=c+\Phi_{1} x_{t-1}+\Phi_{2} x_{t-2}+\cdots+\Phi_{p} x_{t-p}+\varepsilon_{t}
$$

where $x_{t}=\left(z g y_{t}, e o e_{t}, F_{t}\right)^{\prime} z g y_{t}$ denotes the proportion of heavy industrial output in total industrial output value to measures the importance of the industrial structure; eoe $e_{t}$ denotes the conversion efficiency of energy processing to measure the importance of energy structure; $F_{t}$ indicates the comprehensive index of fog-haze risk. $C$ is a $3 \times 1$ dimensional cross-sectional vector, $\Phi_{i}(i=1,2, \cdots, p)$ is a $3 \times 3$ matrix of dimensional coefficient, disturbance term $\varepsilon_{t} \sim$ i.i.d.N $(0, \Omega), \Omega$ is the covariance matrix of $\varepsilon_{t}$.

$$
\mathrm{B}=\left(\begin{array}{ccc}
1 & 0 & 0 \\
0 & 1 & 0 \\
\delta_{10} & \delta_{20} & 1
\end{array}\right)
$$

$B$ denotes that the comprehensive index of fog-haze risk is affected by the current value industrial structure and energy structure, while the industrial

Table 2. Measure index of industrial structure and energy use efficiency.

\begin{tabular}{ccc}
\hline Industrial structure & Heavy industry output value/Total industrial output value & $z g y_{t}$ \\
Energy use efficiency & Conversion efficiency of energy processing & eoe $_{t}$ \\
\hline
\end{tabular}


structure and energy structure are not affected by the current value of other variables. $\delta_{10}, \delta_{20}$ respectively indicate that the comprehensive index of fog-haze risk is affected by the current value of the industrial structure and energy efficiency.

In order to identify the nonlinear and asymmetric effects of industrial structure and energy use efficiency on the comprehensive index of fog-haze risk, based on the smooth migration vector autoregressive model, this work provides a nonlinear smooth migration structure vector autoregressive model to judge the dynamic adjustment mechanism between them.

To better reflect the nonlinear relationship between the comprehensive index of fog-haze risk, industrial structure, and energy structure, the ST-SVAR model was established based on the above model:

$$
\begin{aligned}
z g y_{t}= & \left(\alpha_{0}+\sum_{j=1}^{p} \alpha_{1 j} z g y_{t-j}+\sum_{j=1}^{p} \alpha_{2 j} e o e_{t-j}+\sum_{j=1}^{p} \alpha_{3 j} F_{t-j}\right)\left(1-F\left(z_{1 t-d} ; \gamma_{1}, c_{1}\right)\right) \\
& +\left(\alpha_{0}^{*}+\sum_{j=1}^{p} \alpha_{1 j}^{*} z g y_{t-j}+\sum_{j=2}^{p} \alpha_{2 j}^{*} e o e_{t-j}+\sum_{j=1}^{p} \alpha_{3 j}^{*} F_{t-j}\right) F\left(z_{1 t-d} ; \gamma_{1}, c_{1}\right)+\varepsilon_{1 t} \\
\text { eoe }_{t}= & \left(\beta_{0}+\sum_{j=1}^{p} \beta_{1 j} z g y_{t-j}+\sum_{j=1}^{p} \beta_{2 j} e o e_{t-j}+\sum_{j=1}^{p} \beta_{3 j} F_{t-j}\right)\left(1-F\left(z_{2 t-d} ; \gamma_{2}, c_{2}\right)\right) \\
& +\left(\beta_{0}^{*}+\sum_{j=1}^{p} \beta_{1 j}^{*} z g y_{t-j}+\sum_{j=2}^{p} \beta_{2 j}^{*} e o e_{t-j}+\sum_{j=1}^{p} \beta_{3 j}^{*} F_{t-j}\right) F\left(z_{2 t-d} ; \gamma_{2}, c_{2}\right)+\varepsilon_{2 t} \\
F_{t}= & \left(\delta_{0}+\sum_{j=0}^{p} \delta_{1 j} z g y_{t-j}+\sum_{j=0}^{p} \delta_{2 j} e o e_{t-j}+\sum_{j=1}^{p} \delta_{3 j} F_{t-j}\right)\left(1-F\left(z_{3 t-d} ; \gamma_{3}, c_{3}\right)\right) \\
& +\left(\delta_{0}^{*}+\sum_{j=0}^{p} \delta_{1 j}^{*} z g y_{t-j}+\sum_{j=0}^{p} \delta_{2 j}^{*} e o e_{t-j}+\sum_{j=1}^{p} \delta_{3 j}^{*} F_{t-j}\right) F\left(z_{3 t-d} ; \gamma_{3}, c_{3}\right)+\varepsilon_{3 t}
\end{aligned}
$$

where $F\left(z_{t-d} ; \gamma, c\right)$ is a transfer function; $z_{t-d}$ is a transfer variable; $d$ is the lag parameter; $\gamma$ is the slope parameter; $C$ is the position parameter which measures the threshold value of the transition variable in different districts.

The transfer function can be set as a logic function and an exponential function.

Logical transfer function can be expressed as:

$$
F\left(z_{t-d} ; \gamma, c\right)=\left\{1+\exp \left[-\gamma\left(z_{t-d}-c\right)\right]\right\}^{-1}, \gamma>0
$$

Index transfer function can be expressed as:

$$
F\left(z_{t-d} ; \gamma, c\right)=1-\exp \left[-\gamma\left(z_{t-d}-c\right)\right]^{2}, \gamma>0
$$

The value of the transfer function is between 0 and 1 , which reflects the smooth transition between the parameters in the model. After determining the transfer variables of each variable and performing the setting test of the transfer function, the form of the transfer function is finally determined.

\section{Empirical Results}

Based on the above-mentioned theoretical analysis and research methods, we 
obtain the data of Shaanxi Province from 2006 to 2017 to empirically analyze the impact of economic development on environmental pollution, and so as to provide path options for structural reforms on the supply side.

\subsection{Data Acquisition}

We use the data from 2006 to 2017 in Shaanxi Province to construct a comprehensive index of fog-haze risk and establish a comprehensive index model of fog-haze risk.

First, we obtained the annual average concentration of $\mathrm{PM}_{10}, \mathrm{SO}_{2}, \mathrm{NO}_{2}$, total industrial emissions, industrial sulfur dioxide emissions, industrial smoke and dust emissions, and transportation pressure from 2006 to 2017. Second, we standardized this data. Third, we use principal component analysis to extract the main components that affect fog-haze.

The above data comes from the statistical yearbook of Shaanxi province and the bulletin of the environmental status of Shaanxi province.

Based on the principle that the percentage of accumulated contribution of variance exceeds $85 \%$ [41], we extract the principal components of the three factors. By rotating the factors we obtain a relatively satisfactory common factor.

As can be seen from Table 3, the proportion of traffic pressure in the first principal component is relatively large, which can be summarized as the impact of pollutants on fog-haze risk in the transportation process.

The annual average concentration of $\mathrm{PM}_{10}$ and $\mathrm{NO}_{2}$ accounts for the larger load in the second principal component, which can be summarized as the effect of particulate concentration on fog-haze risk; the proportion of industrial $\mathrm{SO}_{2}$ emissions and industrial dust emissions in the third principal component is relatively large, which can be summarized as the impact of industrial pollutant emissions on fog-haze risk.

After determining the economic significance among the principal components as shown in Table 4, we can obtain the principal component model by combining the component score coefficient matrix as follows:

Table 3. Rotational factor component.

\begin{tabular}{|c|c|c|c|}
\hline \multirow{2}{*}{ Index } & \multicolumn{3}{|c|}{ Composition } \\
\hline & 1 & 2 & 3 \\
\hline$f_{1}$ & -0.09 & 0.922 & 0.046 \\
\hline$f_{2}$ & -0.965 & -0.016 & 0.104 \\
\hline$f_{3}$ & 0.495 & 0.649 & -0.166 \\
\hline$f_{4}$ & 0.913 & -0.114 & -0.321 \\
\hline$f_{5}$ & -0.811 & -0.254 & 0.273 \\
\hline$f_{6}$ & -0.288 & -0.03 & 0.953 \\
\hline$f_{7}$ & 0.953 & 0.162 & -0.199 \\
\hline
\end{tabular}


Table 4. Component score coefficient matrix.

\begin{tabular}{|c|c|c|c|}
\hline \multirow{2}{*}{ Index } & \multicolumn{3}{|c|}{ Composition } \\
\hline & 1 & 2 & 3 \\
\hline$f_{1}$ & -0.12 & 0.718 & 0.017 \\
\hline$f_{2}$ & -0.358 & 0.093 & -0.255 \\
\hline$f_{3}$ & 0.068 & 0.445 & -0.013 \\
\hline$f_{4}$ & 0.263 & -0.187 & -0.038 \\
\hline$f_{5}$ & -0.2 & -0.107 & 0.02 \\
\hline$f_{6}$ & 0.265 & 0.005 & 1.082 \\
\hline$f_{7}$ & 0.298 & 0.02 & 0.13 \\
\hline
\end{tabular}

$$
\begin{gathered}
F_{1}=-0.12 X_{1}-0.36 X_{2}+0.07 X_{3}+0.26 X_{4}-0.2 X_{5}+0.27 X_{6}+0.29 X_{7} \\
F_{2}=0.72 X_{1}+0.09 X_{2}+0.45 X_{3}-0.19 X_{4}-0.11 X_{5}+0.01 X_{6}+0.02 X_{7} \\
F_{3}=0.02 X_{1}-0.26 X_{2}-0.01 X_{3}-0.04 X_{4}+0.02 X_{5}+1.08 X_{6}+0.13 X_{7}
\end{gathered}
$$

The comprehensive index model of fog-haze risk is as follows:

$$
F=\left(0.532 F_{1}+0.196 F_{2}+0.166 F_{3}\right) / 88.66
$$

According to Formula (11), we can get the comprehensive index of fog-haze risk in Shaanxi province from 2006 to 2017. The resulting composite index is more convincing than simply representing fog-haze risk with a single indicator.

Furthermore, we use the Shaanxi Statistical Yearbook from 2007 to 2018 to obtain data on the proportion of heavy industrial output in total industrial output value and energy conversion efficiency from 2006 to 2017.

\subsection{Determination of Lag Order}

By comparing the AIC and SC information criteria, the model has a lag order of two, according to the following Table 5.

When we compare AIC and SC in both cases, the results show that the second-order lag test results are more persuasive Therefore, we determine that the lag order is 2 orders.

\subsection{Linear Test}

Because there are unrecognized redundant parameters in the model, Taylor's approximation was used to test the model linearly.

\subsubsection{Selection Principle}

Taking the fog-haze comprehensive index equation as an example, introduce the linear test of the ST-SVAR model and the selection principle of the transfer variable. Terasvirta and Anderson for the above-mentioned ST-SVAR model [42], a third-order Taylor approximation is performed at $\lambda=0$ as follows: 
Table 5. The test of second order lag.

\begin{tabular}{cccc}
\hline Lag & LogL & AIC & SC \\
\hline 1 & -75.75138 & 17.722 & 17.810 \\
2 & -43.46242 & 12.615 & 12.685 \\
\hline
\end{tabular}

$$
F_{t}=\omega_{0} X+\omega_{1} X z_{3 t-d}+\omega_{2} X z_{3 t-d}^{2}+\omega_{3} X z_{3 t-d}^{3}+v_{t}
$$

where, $\omega_{i}, i=0,1,2,3$ is the corresponding regression coefficient vector. The Taylor equation can be used to perform linear tests on the equations. The null hypothesis is set to:

$$
H_{0}: \omega_{1}=\omega_{2}=\omega_{3}=0
$$

By setting different transition variables, the linear equations and the corresponding constrained regression equations are estimated. The Lagrange multiplier test statistic constructed as follows performs a linear test on the above equation:

$$
L M_{3}=\frac{T\left(S S R_{0}-S S R_{1}\right)}{S S R_{0}} \sim \chi^{2}(3(K-1))
$$

If, the result rejects the null assumption that the model is linear, then the significance probabilities of the statistics corresponding to different transitional variables can be further compared. The variable corresponding to the minimum probabilistic probability is the transitional variable of the model.

\subsubsection{Linear Test Results}

Unit root test of the above three sequences using the ADF test method, and the test results show that these sequences are all stable. After determining the lag order, we perform linear tests for each equation. The included explanatory variables were used as the transfer variables, and the test results are shown in $\mathrm{Ta}$ ble 6 below.

For the fog-haze risk comprehensive index equation, when $e o e_{t-1}$ is used as the transfer variable, the LM standard linear test rejects the model as a linear null hypothesis with a significance level of $10 \%$; when $z g y_{t-1}$ is used as a transfer variable, the LM standard linear test also rejects the model as a linear hypothesis with a significance level of $10 \%$. According to the principle of least probabilistic probability, the transition variable of the Fog-haze risk comprehensive index equation is set to $e o e_{t-1}$. For the industrial structure equation, when $z g y_{t-1}$ is used as the transfer variable, the LM linear test rejects the original assumption that the model is linear with a significance level of $10 \%$. Therefore, the transfer variable of the industrial structural equation is set to $z g y_{t-1}$. For the energy use efficiency equation, when $e o e_{t-1}$ is used as a transfer variable, the standard linear test rejects the linear assumption of the model with a significance level of $10 \%$. Similarly, the transfer variable of the energy structure equation is set to eoe $_{t-1}$. 
Table 6. Selection of linear tests and transfer variables.

\begin{tabular}{cccc}
\hline \multirow{2}{*}{ Transfer variable } & $\begin{array}{c}\text { Fog-haze risk comprehensive } \\
\text { index equation }\end{array}$ & $\begin{array}{c}\text { Industrial } \\
\text { structure equation }\end{array}$ & $\begin{array}{c}\text { Energy use } \\
\text { efficiency equation }\end{array}$ \\
\cline { 2 - 4 }$F_{t-1}$ & $9.99(0.11)$ & $L M_{3}$ & \\
$F_{t-2}$ & $9.97(0.14)$ & $9.54(0.01)$ & $9.76(0.70)$ \\
$z g y_{t}$ & $9.52(0.01)$ & $9.75(0.08)$ & $9.82(0.29)$ \\
$z g y_{t-1}$ & $9.88(0.01)$ & - & - \\
$z g y_{t-2}$ & $9.33(0.62)$ & $9.83(0.00)$ & $9.98(0.05)$ \\
eoe & $9.99(0.02)$ & $9.99(0.07)$ & $9.98(0.70)$ \\
eoe $e_{t-1}$ & $8.58(0.00)$ & - & - \\
eoe $_{t-2}$ & $9.93(0.09)$ & $6.59(0.04)$ & $5.82(0.03)$ \\
\hline
\end{tabular}

\subsection{Transfer Function}

After determining the final transfer variable, select the transfer function according to the verification procedure given by Terasvitta and Anderson, and set the constraint test as follows:

$$
\begin{gathered}
H_{01}: \theta_{3}=0 \\
H_{02}: \theta_{2}=0 \mid \theta_{3}=0 \\
H_{03}: \theta_{1}=0 \mid \theta_{2}=\theta_{3}=0
\end{gathered}
$$

For the above constraint test, if the corresponding significance probability of the test $H_{02}$ is the smallest, the transfer function selects the form of the exponential function. Conversely, the transfer function is set as the form of the logistic function.

According to the transition variables determined in the linear test, set the transfer function for each equation and test them. The test results are shown in the following Table 7.

In the case of Hypothesis 1 and Hypothesis 2, the test value of the fog-haze risk comprehensive equation is greater than 0.04 (Hypothesis 3). That is, according to the principle of minimum value, the fog-haze risk comprehensive index equation rejects $H_{03}$ at the significance level of $10 \%$, so the transfer function of the fog-haze risk comprehensive index equation is set as the logic function form.

According to the principle of taking the minimum value, the test value of the Hypothesis 3 is in accordance with the selection condition. It can determine the transfer function of the energy use efficiency equation also in the form of a logical function.

However, for the industrial structural equation, the minimum value appears in the case of Hypothesis 2, it rejects $H_{02}$ at the significance level of $10 \%$, so set 
Table 7. Results of model transfer function setting test.

\begin{tabular}{|c|c|c|c|}
\hline Null hypothesis & $\begin{array}{l}\text { Fog-haze risk } \\
\text { comprehensive } \\
\text { index equation }\end{array}$ & $\begin{array}{c}\text { Industrial } \\
\text { structure } \\
\text { equation }\end{array}$ & $\begin{array}{c}\text { Energy use } \\
\text { efficiency equation }\end{array}$ \\
\hline$H_{01}: \theta_{3}=0$ & $\begin{array}{c}10.71^{\star *} \\
(0.57)\end{array}$ & $\begin{array}{l}2.18^{\star *} \\
(0.05)\end{array}$ & $\begin{array}{l}5.88^{\star *} \\
(0.07)\end{array}$ \\
\hline$H_{02}: \theta_{2}=0 \mid \theta_{3}=0$ & $\begin{array}{c}11.68^{*} \\
(0.52)\end{array}$ & $\begin{array}{l}1.16^{\star *} \\
(0.02)\end{array}$ & $\begin{array}{l}3.61^{\star *} \\
(0.01)\end{array}$ \\
\hline$H_{03}: \theta_{1}=0 \mid \theta_{2}=\theta_{3}=0$ & $\begin{array}{l}1.65^{\star *} \\
(0.04)\end{array}$ & $\begin{array}{l}0.36^{\star *} \\
(0.29)\end{array}$ & $\begin{array}{l}0.97^{\star *} \\
(0.00)\end{array}$ \\
\hline
\end{tabular}

the transfer function of the industrial structure equation to the form of an exponential function.

\subsection{Results}

Aiming at the nonlinear ST-SVAR model, use a system estimation method that simultaneously estimates all parameters in the model equation.

Before estimating the parameters, we need to scale the transfer function in order to avoid the influence of the dimension of the transfer variable on the slope parameter $\gamma$.

The scaled logic transfer function is as follows:

$$
F\left(z_{t-d} ; \gamma, c\right)=\left\{1+\exp \left[-\gamma \frac{\left(z_{t-d}-c\right)}{\sigma_{z_{t}}}\right]\right\}^{-1}, \gamma>0
$$

The scaled index transfer function is as follows:

$$
F\left(z_{t-d} ; \gamma, c\right)=1-\exp \left[-\gamma \frac{\left(z_{t-d}-c\right)}{\sigma_{z_{t}}}\right]^{2}, \gamma>0
$$

were, $\sigma_{z_{t}}$ denotes the sample standard deviation of the corresponding transfer variable.

Considering that there may be a correlation between the various equations in the ST-SVAR model, the full information maximum likelihood method is used to estimate the parameters of the model. The estimated results are shown in Table 8.

Aiming at the fog-haze risk comprehensive equation, the impact of fog-haze risk itself is relatively slight, but, the industrial structure and energy use efficiency have a great impact on fog-haze risk. Reflecting the severe problems in the industrial structure at the current stage, it causes serious pollution to the environment. The impact of industrial structure and energy use efficiency on the risk of fog-haze has continued to expand with the passage of time.

Aiming at the industrial structural equations, fog-haze comprehensive risk and energy use efficiency has little impact on it. The industrial structure has a great influence on itself. This effect has not diminished with the passage of time. 
Table 8. Estimation results of ST-SVAR model.

\begin{tabular}{ccccccc}
\hline \multirow{2}{*}{ Variables } & \multicolumn{2}{c}{$\begin{array}{c}\text { Fog-haze risk } \\
\text { comprehensive index equation }\end{array}$} & \multicolumn{2}{c}{$\begin{array}{c}\text { Industrial } \\
\text { structure equation }\end{array}$} & \multicolumn{2}{c}{$\begin{array}{c}\text { Energy use } \\
\text { efficiency equation }\end{array}$} \\
\cline { 2 - 7 } & $\begin{array}{c}\text { Estimated } \\
\text { value }\end{array}$ & $\begin{array}{c}\text { Standard } \\
\text { deviation }\end{array}$ & $\begin{array}{c}\text { Estimated } \\
\text { value }\end{array}$ & $\begin{array}{c}\text { Standard } \\
\text { deviation }\end{array}$ & $\begin{array}{c}\text { Estimated } \\
\text { value }\end{array}$ & $\begin{array}{c}\text { Standard } \\
\text { deviation }\end{array}$ \\
\hline int & 12.873 & 6.013 & 28.145 & 0.39 & 35.513 & 1.73 \\
$F_{t-1}$ & 0.99 & 3.399 & 0.037 & 0.061 & 0.035 & 0.269 \\
$F_{t-2}$ & 0.98 & 0.75 & -0.000 & 0.004 & -0.009 & 0.016 \\
$z g y_{t}$ & -28.29 & 9.32 & - & - & - & - \\
$z g y_{t-1}$ & 26.515 & 5.296 & 0.99 & 1.63 & 0.93 & 7.15 \\
$z g y_{t-2}$ & 52.803 & 9.196 & 0.99 & 0.81 & -0.116 & 3.856 \\
eoe $_{t}$ & -17.464 & 9.40 & - & - & - & - \\
eoe $_{t-1}$ & 28.366 & 8.098 & 1.069 & 1.75 & 0.98 & 7.65 \\
eoe $_{t-2}$ & 11.247 & 8.276 & 0.41 & 0.53 & 0.99 & 2.33 \\
\hline
\end{tabular}

Aiming at the energy use efficiency equations, energy use efficiency has greater impact on it. Fog-haze comprehensive risk and industrial structure equation also has an impact on it, but its role gradually diminishes over time.

Although some of the regression coefficients are not significant, that, do not affect the significant results of the overall regression coefficients. Therefore, the rationality of the establishment of non-linear ST-SVAR model was verified and three equations were obtained. According to Table 8, we can get the following result:

$$
\mathrm{B}=\left(\begin{array}{ccc}
1 & 0 & 0 \\
0 & 1 & 0 \\
\delta_{10} & \delta_{20} & 1
\end{array}\right) \rightarrow \mathrm{B}=\left(\begin{array}{ccc}
1 & 0 & 0 \\
0 & 1 & 0 \\
-28.29 & -17.464 & 1
\end{array}\right)
$$

This explains that the comprehensive index of fog-haze risk is affected by the current industrial structure and energy structure. The coefficients of the industrial structure and energy use efficiency equations are all relatively small, indicating that they are affected little by the current value of other variables. $\delta_{10}$, $\delta_{20}$ are respectively $-28.29,-17.464$, which shows that the industrial structure, energy use efficiency has great impact on the comprehensive index of fog-haze risk.

\section{Conclusions and Policy Implications}

This work cites a nonlinear ST-SVAR model that discusses the relationship between industrial structure, energy use efficiency, and haze risk. The results are shown below:

1) Current industrial structure and energy use efficiency have greater impact 
on the comprehensive equation of fog-haze risk than itself. With the passage of time, this influence is still gradually expanding.

2) The non-linear or asymmetric relationship is shown among industrial structure, energy use efficiency, and the fog-haze comprehensive risk equation.

3) To solve the fog-haze pollution, the supply-side reform is imperative.

Based on the above discussion, the following are the suggestions for the path selection of the government's supply side reform:

First, Industrial Structure Adjustment: Industrial structure adjustment measures promote the development of the tertiary industry while reducing the expansion of heavy industry, and improve the service of residents, water conservancy, environment and public facilities management. The government should guide the green development of modern enterprises and deepen the reform of industrial supply. It needs to coordinate the relationships between the three industries and strengthen the environmental protection mechanism.

Second, Energy Technological Innovation: The backward development of energy technology not only brings about environmental pollution, but also wastes a lot of natural resources. The government should vigorously support the use of clean energy technologies and provide local companies with access to technology, tax relief, and expert hiring, and deepen the reform of the existing processing model, and promote the deep processing of energy, and provide the public with more neatness and convenient services.

Third, Institutional construction: To strengthen the construction of environmental supervision teams and to optimize the personnel allocation. The government should strengthen the long-term authoritative supervision mechanism and combine the preventive supervision in advance, the procedural supervision in the event, and the post-acquisition and punishment supervision. It should also improve the accountability mechanism for environmental protection.

Fourth, Improve the Macro-control System: To deepen the reform of fiscal, taxation, financial, investment, and financing systems, the government will improve the budget decision and management system, increase investment in environmental protection. Aiming at companies with low environmental pollution, and imposing penalties for additional taxation on companies with serious environmental pollution, the government should provide support for tax deductions to stimulate healthy competition in different areas.

\section{Acknowledgements}

This research is supported by the National Natural Science Foundation of China, "Fractional-order stochastic dynamics modeling and analysis of economic-environmental systems" (Nos. 11572231).

\section{Conflicts of Interest}

The authors declare no conflicts of interest regarding the publication of this paper. 


\section{References}

[1] Zhao, J.L., Zhao, J. and Xue, F. (2018) Fog-Haze Pollution, Energy Consumption and Economic Growth: Policy Review and Empirical Research. Consumer Economics, 34, 3-11.

[2] Kutty, S.G., Agnihotri, G. and Dimri, A.P. (2018) Fog Occurrence and Associated Meteorological Factors over Kempegowda International Airport, India. Pure and Applied Geophysics, 3, 1-12. https://doi.org/10.1007/s00024-018-1882-1

[3] Guan, X., Nie, H.L., Song, L.L. and Gao, N. (2016) Discussion on the Adjustment Measures of Fog-Haze Energy Structure in Beijing. District Heating, 1, 23-28.

[4] Li, M. (2018) Study on the Causes and Effects of Fog-Haze Weather. Henan Science and Technology, 634, 152-153.

[5] Tong, J., Liu, W. and Xue, J. (2016) Environmental Regulation, Factor Input Structure and Industrial Transformation. Economic Research Journal, 7, 43-57.

[6] Zhang, W., Zhu, Q.G. and Gao, Q. (2016) Upgrading of Industrial Structure, Optimizing of Energy Structure, and Low Carbon Development of Industrial System. Economic Research Journal, 12, 62-75.

[7] Gui, H. (2017) The Effectiveness, Problems and Suggestions of China's Energy Efficiency. Macroeconomic Management, 12, 41-46.

[8] Chu, M.Q. (2016) Industrial Development, Factor Input and China's Supply Side Reform. Truth Seeking, 6, 33-39.

[9] Chen, S.M. and He, L.Y. (2017) Environment, Health, and Economic Growth: The Optimal Allocation of Energy Tax Revenue. Economic Research Journal, 4, 120-134.

[10] Liu, H.Z., Yang, G.L. and Yin, L. (2014) Government Debt, Economic Growth and Non-Linear Effects. Statistical Research, 31, 29-38.

[11] Wang, S.B. and Xu, Y.Z. (2015) Environmental Regulation and the Decoupling Effect of Smog: Based on the Perspective of Enterprise Investment Preference. China Industrial Economics, 325, 18-30.

[12] Cao, C.H. and Han, L.Y. (2015) Estimation of Social Health Costs from Fog-Haze. Statistical Research, 32, 19-23.

[13] Peng, J.Y., Zhang, Y.G., Xie, R. and Liu, Y. (2018) Analysis of Driving Factors on China's Air Pollution Emissions from the View of Critical Supply Chains. Journal of Cleaner Production, 203, 197-209. https://doi.org/10.1016/j.jclepro.2018.08.219

[14] Sharifah, R.W.A., Jiří, J.K. and Petar, S.V. (2016) Cleaner Energy Planning, Management and Technologies: Perspectives of Supply-Demand Side and End-of-Pipe Management. Journal of Cleaner Production, 136, 1-13. https://doi.org/10.1016/j.jclepro.2016.07.181

[15] Wu, Y.P. and Zhang, Y. (2017) Path Choice and Policy Design of China's Energy Supply Side Reform. Resource Development \& Market, 8, 969-973.

[16] Melike, E.B. and Seyit, M.G. (2017) Environmental Pollution, Hydropower Energy Consumption and Economic Growth: Evidence from G7 Countries. Renewable and Sustainable Energy Reviews, 75, 68-85. https://doi.org/10.1016/j.rser.2016.10.052

[17] Craig, D.R. and Tim, J. (2018) A Review of EROEI-Dynamics Energy-Transition Models. Energy Policy, 122, 260-272. https://doi.org/10.1016/j.enpol.2018.06.041

[18] Zheng, S.N., Lam, C., Hsu, S. and Ren, J.Z. (2018) Evaluating Efficiency of Energy Conservation Measures in Energy Service Companies in China. Energy Policy, 122, 580-591. https://doi.org/10.1016/j.enpol.2018.08.011

[19] Wouter, P., Alexa, S., Christina, D. and Nick, F.P. (2012) Individual-Motivational 
Factors in the Acceptability of Demand-Side and Supply-Side Measures to Reduce Carbon Emissions. Energy Policy, 48, 812-819. https://doi.org/10.1016/j.enpol.2012.06.029

[20] Song, M.L., Du, Q.Q. and Jin, P.Z. (2016) Environmental Economy and Natural Resource Management from the Perspective of Supply Side Structural Reform. Economic Research Journal, 4, 188-192.

[21] Liu, F., Lv, T., Muhammad, S. and Li, X.X. (2018) Optimization for China's Coal Flow Based on Matching Supply and Demand Sides. Resources, Conservation and Recycling, 129, 345-354. https://doi.org/10.1016/j.resconrec.2016.08.013

[22] Zhang, Y.Q., Liu, C.G., Li, K. and Zhou, Y. (2018) Strategy on China's Regional Coal Consumption Control: A Case Study of Shandong Province. Energy Policy, 122, 316-327. https://doi.org/10.1016/j.enpol.2017.10.035

[23] Yu, S.W., Zheng, S.H., Zhang, X.J., Gong, C.Z. and Cheng, J.H. (2018) Realizing China's Goals on Energy Saving and Pollution Reduction: Industrial Structure Multi-Objective Optimization Approach. Energy Policy, 122, 300-312. https://doi.org/10.1016/j.enpol.2018.07.034

[24] Liu, C., Hong, T., Li, H.F. and Wang, L.L. (2018) From Club Convergence of per Capita Industrial Pollutant Emissions to Industrial Transfer Effects: An Empirical Study across 285 Cities in China. Energy Policy, 121, 300-313. https://doi.org/10.1016/j.enpol.2018.06.039

[25] Ji, X., Yao, Y.X. and Long, X.L. (2018) What Causes PM2.5 Pollution? Cross-Economy Empirical Analysis from Socioeconomic Perspective. Energy Policy, 119, 458-472.

[26] Ma, L.M., Liu, S.L. and Zhang, X. (2016) Energy Structure, Traffic Model and Haze Pollution-Based on Spatial Econometric Model. Finance \& Trade Economics, 1, 147-160.

[27] Li, Y., Chiu, Y. and Lu, L.C. (2018) Energy and AQI Performance of 31 Cities in China. Energy Policy, 122, 194-202. https://doi.org/10.1016/j.enpol.2018.07.037

[28] Raphael, J.H. (2018) The Application of Distributive Justice to Energy Taxation Utilising Sovereign Wealth Funds. Energy Policy, 122, 649-654. https://doi.org/10.1016/j.enpol.2018.07.049

[29] Ram, M.S. and Charles, O.P.M. (2005) Supply- and Demand-Side Effects of Power Sector Planning with Demand-Side Management Options and $\mathrm{SO}_{2}$ Emission Constraints. Energy Policy, 33, 815-825. https://doi.org/10.1016/j.enpol.2003.10.007

[30] Lin, W.B. and Su, J. (2015) Understanding Supply Side Reform: An Energy Perspective. Price Theory \& Practice, 378, 8-11.

[31] Liu, X.Y. (2017) Breakthrough of Industrial Structure Adjustment Dilemma with Supply-Side Structural Reform. South China Finance. http://www.cnki.net/kcms/detail/44.1479.F.20170217.1409.008.html

[32] Xu, Z.S. and Kong, F.B. (2014) Economic Development Level, Industrial Structure and Environmental Pollution: An Empirical Analysis Based on Jiangxi Province. Contemporary Finance \& Economics, 8, 15-20.

[33] Leng, Y.L. and Du, S.Z. (2015) Industrial Structure, Urbanization and Fog-Haze Pollution. Forum on Science and Technology in China, 9, 49-55.

[34] Peter, F., Will, G. and Jennifer, H. (2018) Long-Term U.S Transportation Electricity Use Considering the Effect of Autonomous-Vehicles: Estimates \& Policy Observations. Energy Policy, 122, 203-213. https://doi.org/10.1016/j.enpol.2018.07.033

[35] Zhou, M. and Liu, B.L. (2017) Why Is Supply-Side Structural Reform Inevitable? Economic Explanation for Chinese Overcapacity. Economic Research Journal, 2, 
67-81.

[36] Xie, R., Wang, F.F., Julien, C., Zhu, B.Z. and Zhao, G.M. (2018) Supply-Side Structural Effects of Air Pollutant Emissions in China: A Comparative Analysis. Structural Change and Economic Dynamics, 46, 89-95.

https://doi.org/10.1016/j.strueco.2018.04.005

[37] Li, K. and Lin, B.Q. (2016) Impact of Energy Technology Patents in China: Evidence from a Panel Cointegration and Error Correction Model. Energy Policy, 89, 214-223. https://doi.org/10.1016/j.enpol.2015.11.034

[38] Han, L. (2017) Construction and Measurement of Fog-Haze Disaster Risk Index. Statistics \& Decision, 2, 28-32.

[39] Fan, X.L. and Wu, S.C. (2017) Research on the Relationship between Economic Growth and Fog-Haze Pollution in Shanghai. Development Research, 2, 88-93.

[40] Zhang, X.Y., Liu, J.Q. and Liu, H.Y. (2013) Research on Nonlinear Influence Mechanism of Monetary Policy and Stock Return Rate. Journal of Financial Research, 391, 38-52.

[41] Wang, L.M. and Wang, L. (2009) Application Time Series Analysis. Fudan University Press, Shanghai.

[42] Terasvirta, T. and Anderson, H.M. (1992) Characterizing Nonlinearities in Business Cycles Using Smooth Transition Autoregressive Models. Journal of Applied Econometrics, 7, 119-136. https://doi.org/10.1002/jae.3950070509 